\title{
Impact of traveller information on mode choice behaviour
}

\author{
Meng Meng BEng, PhD \\ Research Fellow, TUM CREATE, Singapore; Centre for Infrastructure \\ Systems, School of Civil and Environmental Engineering, Nanyang \\ Technological University, Singapore (corresponding author: \\ mengm@ntu.edu.sg)
}

Abdul Ahad Memon BEng, MSc, PhD

Road Safety Specialist, Technical Cooperation Program of EU for Road Sector Development Program of Ethiopia, SMEC International (Pty) Ltd., Ethiopian Roads Authority, Addis Ababa, Ethiopia
Yiik Diew Wong BEng, PhD

Associate Professor, Centre for Infrastructure Systems, School of Civil and Environmental Engineering, Nanyang Technological University, Singapore

Soi-Hoi Lam BEng, MSc, PhD

Adjunct Professor, University of Macau, Avenida da Universidade, Taipa, Macau, China

This paper analysed automobile commuters' mode choice behaviour under the influence of simulated multimodal traveller information by developing two logit models. A combined revealed preference (RP)/stated preference (SP) travel behaviour survey was administered to drivers to gather individual commuters' travel decisions under integrated multimodal traveller information. Two SP scenarios were designed where the first scenario is to test the mode choice preference in a basic situation involving a congested work/school trip with information on several travel options, and the second scenario is to investigate the mode choice decision when certain incentives are given for public transport. Results showed that integrated multimodal traveller information can influence a traveller's mode choice decision. The influencing factors that significantly affect the mode choice decision include socio-economic characteristics - for example, gender, age, level of education and level of income - and multimodal traveller information attributes - for example, access mode to mass rapid transit (MRT) station, access time to MRT station and transit seat availability. The findings are useful to traffic management agencies for designing better operational policy and information publication strategies.

$\begin{array}{ll}\text { Notation } \\ P & \text { upper bound of the probability of making a } \\ & \text { type 1 error } \\ \mathrm{TC}_{\mathrm{PB}} & \text { travel cost by public mode of transport } \\ \mathrm{TC}_{\mathrm{PR}} & \text { travel cost by private mode of transport } \\ \mathrm{TT}_{\mathrm{PB}} & \text { travel time by public mode of transport } \\ \mathrm{TT}_{\mathrm{PR}} & \text { travel time by private mode of transport } \\ U_{\mathrm{PR}}, U_{\mathrm{PB}} & \text { utility functions for private and public modes of } \\ & \text { transport, respectively } \\ K & \text { upper bound of the number of the variable } \\ k & \text { variable involved in the interaction } \\ x & \text { variable } \\ \beta & \text { coefficient } \\ \rho^{2} & \text { pseudo } r \text {-squared value } \\ \chi^{2} & \chi \text {-squared value }\end{array}$

\section{Introduction}

Integrated traveller information, as provided by traffic control centres, serves to assist travellers to plan their trips better. By leveraging the most up-to-date information on network congestion, availability and status of transit modes, opportunities for easy transfer and parking availability, travellers can make smart travel decisions, such as adjusting the travel mode, route and departure time, resulting in saving of travel time and alleviation of traffic congestion.

A number of studies have attempted to explore the potential of traveller information provisions in terms of influencing the ways commuters normally travel (Bifulco et al., 2011; Parvaneh et al., 2012). Jou et al. (2005) found that the effectiveness of traveller information depends on the types and formats of how it is disseminated. Guo (2011) reported that travellers who use public transit had a significant tendency to use the public transit information. Chorus et al. (2013) found that travellers pay more attention to the information type and the information cost. Travellers with a high level of education spend less money than those with only primary school education to acquire traveller information. Research has also been conducted on the impacts of the advanced traveller information system (ATIS) on travel behaviour, mainly focusing on the study of automobile commuters' route choice behaviour. The important factors that influence route choice include: system performance attributes, such as trip time and congestion; experiential factors, such as scheduled delay and familiarity (Buliung and Kanaroglou, 2007); and the nature, extent and quality of ATIS information (Adler, 2001; Golob, 2003; Qin et al., 2013). ATIS information also indirectly influences route choice through users' expectations of system performance and their perception of feedback on actual performance measures on alternative routes (Bradley, 2006).

However, the aforementioned studies did not focus on the impacts of traveller information on commuters' travel choice behaviour, as highlighted by Lam and Memon (2003), Zito et al. (2011) and Balakrishna et al. (2013). More specifically, the interactions among mode choices, among others, have not been satisfactorily captured in most studies, especially when 
the dynamic nature of traffic flows on the road network is considered. Furthermore, in most studies, the impacts of traveller information were observed by providing mode-specific information to designated mode users - for example, the impacts of an ATIS were analysed by providing traveller information regarding private modes to only private mode users (Farag and Lyons, 2008, 2012; Kenyon and Lyons, 2003). In such a framework, where the information is provided for specific modes only, the possibility to study drivers' mode choice behaviour is very limited (Chorus et al., 2006). Considering the existing multimodal nature of transportation systems, for example in urban metropolises like Singapore, where the availability of different modes and the provision of integrated traveller information allows commuters to plan their trips by integrating different modes or to choose between public and private modes of travel, it becomes relevant to study the commuter's mode choice behaviour (Luk and Yang, 2003). As such, this research sets out to explore a more efficient way to estimate the effects of multimodal traveller information, given by an information system such as the advanced multimodal traveller information system (AMTIS), on the commuter's mode choice behaviour, and how it quantitatively affects the transport network.

The objective of this research study is to improve the understanding of the travel characteristics of automobile commuters in a multimodal transportation network, and their behaviour and preferences towards mode choice given integrated traveller information, using Singapore as a case study. The subsequent sections are organised as follows: the travel behaviour survey is briefly described in Section 2 . The preliminary analysis on the mode choice preference is discussed in Section 3. A detailed investigation regarding the influence of integrated traveller information is provided in Section 4. Lastly, conclusions are outlined in Section 5.

\section{Travel behaviour survey}

Commuters' mode decisions are usually dependent on their socio-economic characteristics and travel attributes. It is thus important to understand the sensitivity of these attributes and their influence on an individual's mode choice behaviour. To achieve such an understanding, a travel behaviour survey was conducted. The goal of the survey was to analyse commuters' travel behaviour under the influence of traveller information.

In this regard, two kinds of survey technique were used in this paper: a revealed preference (RP) survey and a stated preference (SP) survey to gather the commuters' travel choice decisions with respect to public as opposed to private modes in a congested but information-rich multimodal transportation environment, specifically considering the influence of integrated traveller information. In the RP section, data on actual choices were obtained from the respondents, so as to facilitate the selection of a reference trip for subsequent SP questions. In the SP section, the selected reference trip was customised in different SP scenarios for each individual respondent. These SP scenarios were then presented to the respondent for which the responses were recorded.

Implementing a valid and reliable RP and SP study requires precise definitions of attributes, attention to presentation of preferential information (ratings, rankings or semantics), efficient experimental design and rigorous statistical analysis. Given the researchers' intention to use the RP and SP data jointly, the desired data were provided in semantic format, and the choice experiment appeared the most suitable because: (a) preferences are expressed in a context similar to that of an RP survey; $(b)$ choices are perceived to be more realistic than ratings or rankings; and (c) the SP method makes it possible in principle to test any discrete choice model structure. In spite of the fact that the choice context was quite typical, in order to ensure greater realism and reliability, a computer-assisted survey instrument was designed. Such an approach provided the facility to customise each SP scenario for every specific respondent, according to the information provided in the RP section during the surveys.

The RP component was divided into four parts in which information about automobile commuters' socio-economic characteristics, usual trip preferences, availability and usage of public and private modes were collected. The information gathered in the RP component was then presented in the SP component while creating different hypothesised scenarios. The hypothesised scenarios were customised for each respondent based on the information provided in the RP section. This approach resulted in creating realistic scenarios which could be conceptualised by the automobile commuters as they reflected on certain parameters that existed in actual situations. There were two SP scenarios, which were designed to collect information on: the mode choice preference (SP1) and the mode choice behaviour under certain incentives on public transport (SP2). The mass rapid transit (MRT), which is the railway system spanning the entire island state, represented the public transit transport in the survey.

The survey instrument was designed and developed using Visual Basic and Microsoft Access. A pilot survey was conducted to ensure that the survey questionnaire was well designed and to provide training to the survey staff. After the questionnaire was satisfactorily amended, the main survey was conducted. Surveyors were assigned to different locations in Singapore to collect data with portable computer notebooks. The participants were randomly selected within a continuous 9-d period, which served to cover all differential influences (by days of the week inclusive of weekend) of external events. A broad demographic mix of participants was selected to ensure that commuters in all major categories were represented. The subjects were selected from the driver population located in the northern and eastern sides of Singapore. The selected subjects were required to have a valid driving licence, and commute 
regularly by private mode of transport. The transportation network simulation model which was the source of the hypothesised scenarios mainly covered the central and northern parts of Singapore. The participants were contacted by the interviewers at various locations, such as petrol stations, car parks of shopping centres and food centres. The surveys took place when the subjects drove to these locations to fill up with fuel, to go shopping or to have their meals. The discussions with the participants were first aimed at highlighting the modal choice and travel behaviour to provide an understanding of the decision-making process for the current modal choices. Then the use of multimodal traveller information and its influence on travel behaviour and modal choice were discussed. After this, the subjects were required to provide their personal characteristics and details about their usual travel plans. Later, hypothetical scenarios representing different traveller information schemes were presented to them and their preferences were gathered. Available data were collected from a total number of 479 respondents.

\section{Mode choice preference modelling}

\subsection{Notation used}

A notation list is provided at the beginning of the paper. For clarification, the acronyms used in the modelling are travel cost difference (TCD) and travel time difference (TTD).

\subsection{Variables selection}

To justify the model variables, a general analysis is conducted. The respondents' socio-economic characteristics that were collected in the survey included: gender, age, level of education, level of income, car ownership, stoppage (refers to a regular compulsory stop that the car driver makes to drop off children at school, spouse at work, or have breakfast before reaching his/her destination), electronic road pricing (ERP) and acceptable delay. The impact of each variable on respondents' mode choice is presented in Table 1, which also provides information about the market segment of each socio-economic variable, distribution with respect to each mode of transport and details of respondents' mode-switching behaviour.

The mode-switching column reflects the comparative percentage of mode-switching respondents within the specific category: for example, based on the gender category, about $48 \%$ of the females exhibited certain degrees of mode-switching behaviour, whereas for males only $17 \%$ of them had any intention of switching their modes of travel. This may imply that females have higher mode-switching propensity as compared to males. Similarly, age, education level and income all seem to influence the mode choice behaviour.

Car ownership also showed some influence on mode choice behaviour. Respondents who did not own cars and drove to work

Table 1. Influence of socio-economic characteristics of auto commuters on mode choice behaviour

\begin{tabular}{|c|c|c|c|c|c|c|}
\hline & & \multirow[b]{2}{*}{$\begin{array}{l}\text { Market segment: } \\
\text { number of car users }\end{array}$} & \multicolumn{2}{|c|}{ Mode choice: number } & \multicolumn{2}{|c|}{ Mode choice: \% } \\
\hline \multicolumn{2}{|c|}{ Socio-economic variables (code) } & & $\begin{array}{l}\text { Switch } \\
\text { to public }\end{array}$ & $\begin{array}{c}\text { Continue } \\
\text { with private }\end{array}$ & $\begin{array}{l}\text { Switch } \\
\text { to public }\end{array}$ & $\begin{array}{c}\text { Continue } \\
\text { with private }\end{array}$ \\
\hline \multirow[t]{2}{*}{ Gender } & Female (0) & 220 & 106 & 114 & $48 \cdot 18$ & $51 \cdot 82$ \\
\hline & Male (1) & 259 & 45 & 214 & $17 \cdot 37$ & 82.63 \\
\hline \multirow[t]{4}{*}{ Age: years } & $18-35(0)$ & 48 & 8 & 40 & $16 \cdot 67$ & $83 \cdot 33$ \\
\hline & $36-45(1)$ & 186 & 104 & 82 & $55 \cdot 91$ & 44.09 \\
\hline & $46-55(2)$ & 235 & 37 & 198 & $15 \cdot 74$ & $84 \cdot 26$ \\
\hline & Above $55(3)$ & 9 & 1 & 8 & $11 \cdot 11$ & 88.89 \\
\hline \multirow[t]{4}{*}{ Education } & Pre-university and below (0) & 75 & 55 & 20 & $73 \cdot 33$ & $26 \cdot 67$ \\
\hline & Bachelors (1) & 142 & 67 & 75 & $47 \cdot 18$ & $52 \cdot 82$ \\
\hline & Masters (2) & 162 & 24 & 138 & $14 \cdot 81$ & $85 \cdot 19$ \\
\hline & $\operatorname{PhD}(3)$ & 100 & 5 & 95 & 5 & 95 \\
\hline \multirow[t]{5}{*}{ Income: $\$ \$ /$ month ${ }^{a}$} & Below 1501 (0) & 23 & 4 & 19 & $17 \cdot 39$ & $82 \cdot 61$ \\
\hline & $1501-3000(1)$ & 69 & 25 & 44 & $36 \cdot 23$ & $63 \cdot 77$ \\
\hline & $3001-6000(2)$ & 174 & 56 & 118 & $32 \cdot 18$ & $67 \cdot 82$ \\
\hline & $6001-12000(3)$ & 186 & 59 & 127 & $31 \cdot 72$ & $68 \cdot 28$ \\
\hline & Above 12000 & 27 & 7 & 20 & $25 \cdot 93$ & 74.07 \\
\hline \multirow[t]{2}{*}{ Car ownership } & Yes (1) & 418 & 128 & 290 & $30 \cdot 62$ & $69 \cdot 38$ \\
\hline & No $(0)$ & 60 & 23 & 37 & $38 \cdot 33$ & $61 \cdot 67$ \\
\hline \multirow[t]{2}{*}{ Stoppage } & Yes (1) & 4 & 0 & 4 & 0 & 100 \\
\hline & No (0) & 475 & 151 & 324 & $31 \cdot 79$ & $68 \cdot 21$ \\
\hline \multirow[t]{2}{*}{ Pay ERP charges } & Yes (1) & 285 & 82 & 203 & $28 \cdot 77$ & $71 \cdot 23$ \\
\hline & No (0) & 194 & 70 & 124 & $36 \cdot 08$ & 63.92 \\
\hline \multirow[t]{3}{*}{ Acceptable delay: min } & $5(0)$ & 161 & 43 & 118 & $26 \cdot 71$ & $73 \cdot 29$ \\
\hline & $10(1)$ & 229 & 82 & 147 & $35 \cdot 81$ & $64 \cdot 19$ \\
\hline & $15(2)$ & 90 & 27 & 63 & 30 & 70 \\
\hline
\end{tabular}


were more inclined to change their mode as compared to those who did own cars. However, respondents who made regular stops were less willing to change their mode of transport. Such behaviour can be due to the commitment that they might have, such as dropping their children at school or taking their spouses to work. Surprisingly, those who did not have to pay ERP charges were more inclined towards mode switching. It can be observed that acceptable delay did influence the mode-switching behaviour, but not in direct relation to the magnitude of delay. By aggregating the data into two groups based on gender (i.e. male and female), the influence of age, education and income on mode choice behaviour can be further analysed.

Two factors regarding the travel characteristics, namely, estimated time saving and estimated cost saving, were recorded in the survey. The empirical findings as presented in Figure 1 show that information on both of these two factors attracted the respondents to switch from their usual mode. Information on increase in estimated time saving attracted the commuters towards a propensity to a higher degree of mode switching; an

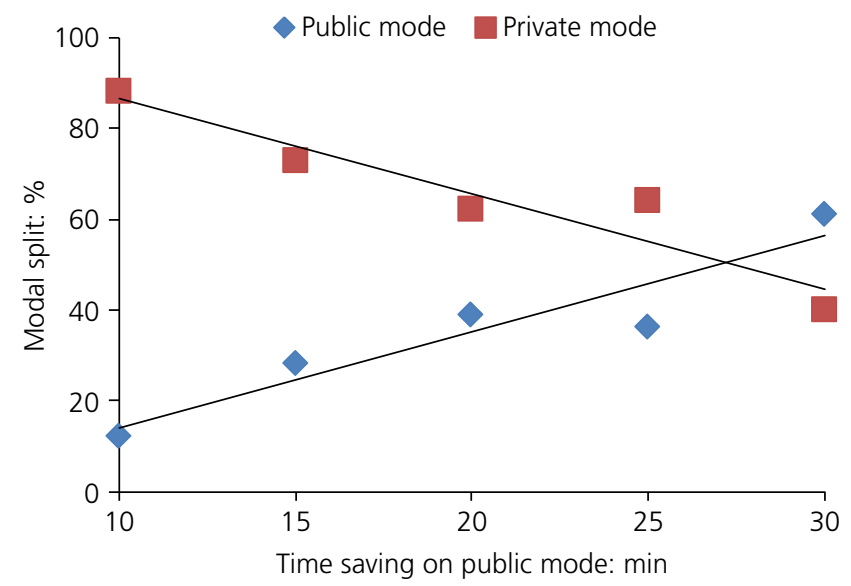

(a)

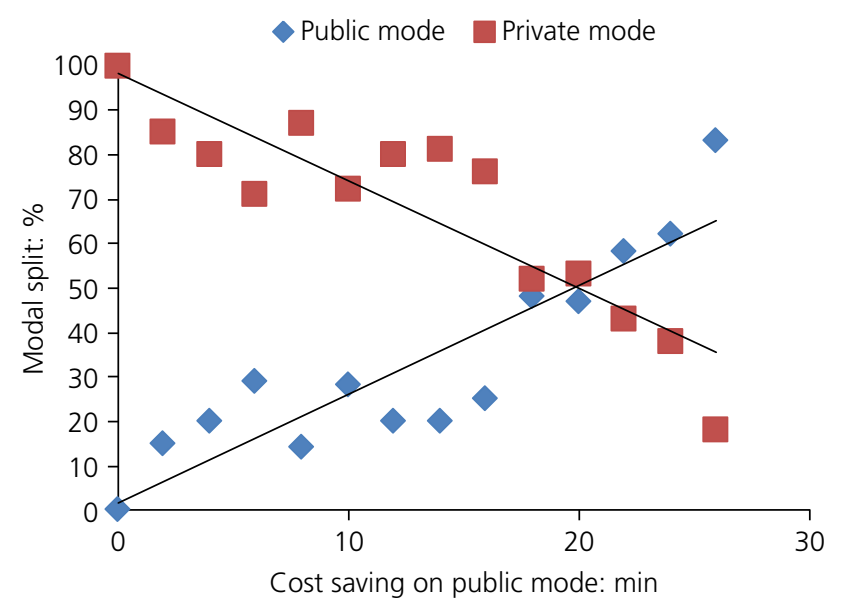

Figure 1. Impact of estimated time and cost saving on commuters' mode-switching propensity increase in cost saving also attracted the respondents to change their mode of transport.

To explore further the impact of public (transit) mode facility, respondents were given information on transit waiting time and seat availability. The impact of waiting time and seat availability is shown in Figure 2. It can be observed that information on waiting time and seat availability both had a significant influence on the mode-switching propensity. A high proportion of the respondents, that is $51 \%$, chose the transit mode when they were given the information that the waiting time was $1 \mathrm{~min}$ and seats were available, whereas $50 \%$ of the respondents chose the transit mode with the same waiting time, but without the availability of seats. At a lower waiting time, the seat availability did not show any significant impact on mode-switching propensity. This reflects that commuters expect a higher level of service when waiting times are longer, and make a trade-off between the transit level of service and their usual mode of travel, when making any mode-switching decision.

\subsection{Binary logit model development}

In order to extend the study on the impact of integrated traveller information on automobile commuters' mode choice behaviour, it is necessary to identify whether or not the integrated traveller information can influence an automobile commuter's willingness to switch his/her mode of travel in a congested road environment. The automobile commuter's personal and travel characteristics that may influence the mode choice decisions, under the influence of multimodal traveller information, will be discussed first. With only public and private mode data under consideration, a binary logit model was estimated to analyse the effect of socio-economic and travel characteristics.

The scenario SP1, which refers to a congested work/school trip with information on several travel options, was administered and the respondents were given a choice between using a private car on the expressway, public rail transit and their usual choices of transport (no inclination to make a choice for the latter). The total number of useable responses was 400 , out of which 245

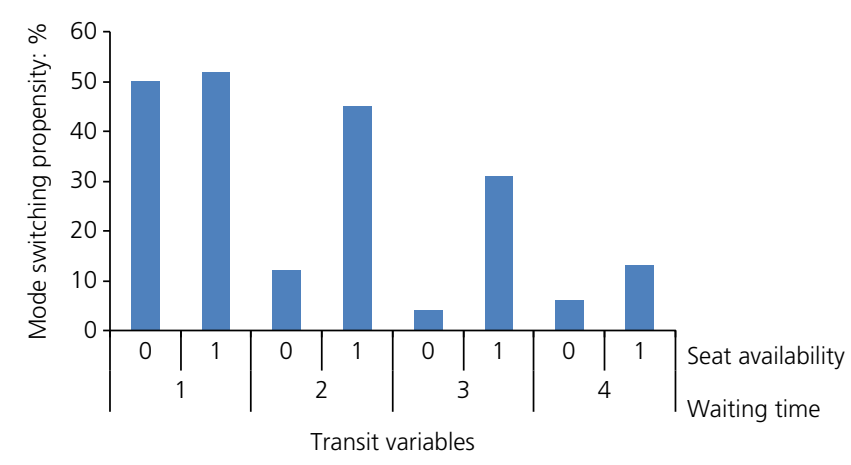

Figure 2. Impact of waiting time (min) and seat availability ( 1 if seat is available, else 0 ) on mode-switching propensity 
selected private (car) mode of transport, 115 selected public (transit) mode of transport and 40 opted for their usual pattern of travel. Excluding the 40 responses, the remaining 360 responses were used for estimating the model. With public and private mode data under consideration, binary logit models were developed based on two types of input parameters: the first was related to the automobile commuter's socio-economic characteristics and the second was related to transport facility characteristics. Different socio-economic and transport-facilityrelated variables were considered while estimating the model, and based on their levels of significance some of them were incorporated in the final model. The socio-economic variables used in the final model were gender, age, level of education and level of monthly personal income. The transport facility characteristics were total trip time and total travel cost. The estimated mode choice model is presented in Table 2.

All the estimated coefficients were significant at the $10 \%$ significance level. The value of $\rho^{2}$ was very high, and this implied that the model could describe the mode choice process well. The utility functions for the private $\left(U_{\mathrm{PR}}\right)$ and public $\left(U_{\mathrm{PB}}\right)$ modes of transport were

$$
\begin{aligned}
U_{\mathrm{PR}}= & 11.531-3 \cdot 361(\text { Travel time })_{\mathrm{PR}}-0.985(\text { Cost })_{\mathrm{PR}} \\
& +2.472(\text { Gender })+1.921(\text { Age }) \\
& +2 \cdot 076(\text { Education })+0.503(\text { Income })
\end{aligned}
$$

\section{2. $U_{\mathrm{PB}}=-3 \cdot 361(\text { Travel time })_{\mathrm{PB}}-0 \cdot 985(\text { Cost })_{\mathrm{PB}}$}

The results as presented in Table 2 showed that, in a noncongested road environment, automobile commuters preferred to

\begin{tabular}{|c|c|c|}
\hline Socio-economic characteristics & Coefficients, $\beta$ & t-Statistics \\
\hline Constant & $11 \cdot 531$ & 1.941 \\
\hline Gender (ref. = female) & $2 \cdot 472$ & $1 \cdot 863$ \\
\hline $\begin{array}{l}\text { Age (ref. = age group } 18 \\
\text { to } 35 \text { years) }\end{array}$ & 1.921 & 1.958 \\
\hline $\begin{array}{l}\text { Level of education } \\
\text { (ref. = pre-university and below) }\end{array}$ & $2 \cdot 076$ & $2 \cdot 735$ \\
\hline $\begin{array}{l}\text { Level of income }(\text { ref. }=\text { income } \\
\text { group less than } \$ \$ 1500)\end{array}$ & 0.503 & $1 \cdot 832$ \\
\hline Transport facility attributes & Coefficients, $\beta$ & t-Statistics \\
\hline Travel time & $-3 \cdot 36$ & $-2 \cdot 464$ \\
\hline Travel cost: $\$ \$$ & -0.985 & -1.937 \\
\hline Summary statistics & & \\
\hline Number of observations & \multicolumn{2}{|l|}{360} \\
\hline Log likelihood function & \multicolumn{2}{|l|}{$-11 \cdot 39$} \\
\hline Restricted log likelihood & \multicolumn{2}{|l|}{$-249 \cdot 53$} \\
\hline Degrees of freedom & \multicolumn{2}{|l|}{354} \\
\hline$\chi^{2}$ & \multicolumn{2}{|c|}{$100 \cdot 665$} \\
\hline$\rho^{2}$ & \multicolumn{2}{|c|}{0.815} \\
\hline
\end{tabular}

Table 2. Binary logit model estimating the commuter's mode choice behaviour under multimodal traveller information take a private mode of transport, but with increase in travel time the likelihood of taking the private mode of transport decreased. The constant term reflected that, if all the variables in Equations 1 and 2 were equal, the automobile commuters would choose the private mode of transport, which corroborated the results of other studies. This may be attributable to the higher level of comfort and freedom in car mobility (Beirão and Cabral, 2007; De Witte et al., 2013). Among the socio-economic variables, the coefficient for gender had a positive sign, which reflected that males were more inclined to use the private mode of transport as compared to females. It may be that men had greater access to vehicles. Similarly, the estimated coefficients for age, income and education had positive signs, which reflected that, with increase in age, income and education, the probability of choosing the private mode of transport became higher. Thus, it can be concluded that, in a congested environment and with higher car cost, automobile commuters who belonged to younger age groups, lower income groups and had lower levels of education might show a higher likelihood to choose the public mode of transport, which is more reliable than the private car in Singapore under conditions of congestion. Commuters with higher income have lower probabilities of choosing public transit, which might be attributed to considerations of comfort, the ready availability of a car and a lower sensitivity to travel cost. The public mode of transport has two main attributes: travel time and travel cost. In a congested environment, the transit mode may be attractive if it has a shorter travel time and lower travelling cost as compared to the private mode of transport. The public mode can become attractive by increasing the travelling cost of the private mode of transport. For example, increasing the ERP or parking charges can directly increase the attraction of the public mode of transport.

The estimated model shown in Table 2 indicates a potential for multimodal traveller information to influence automobile commuters' mode-switching propensity from a private to a public mode of transport. In essence, all of the surveyed sociodemographic attributes affect the automobile commuter's mode-switching propensity; these attributes are gender, age, education, income, travel time and travel cost.

\section{Impact of integrated traveller information on the commuter's mode choice behaviour}

In this section, the impacts of integrated traveller information on an automobile commuter's mode choice behaviour in a congested travel environment are examined. In this regard, the automobile commuters were presented with a hypothesised scenario (SP2), which presented the same delayed work/school trips along with the integrated traveller information as in SP1. In this scenario (SP2), however, certain incentives were given for the public mode of transport. The information provided to the automobile commuters regarding the access time to public mode of transport was randomly reduced by 10,30 and $50 \%$. Similarly, the parking cost and ERP charges were randomly increased by 50, 75 and $100 \%$. The automobile commuters were given a 
choice between private mode, public mode and their usual mode of transport. In total, 400 commuters participated, and they were those commuters who had either chosen the private mode or the public mode of transport in the previous SP. A binary logit model was developed to capture the mode choices based on two types of input parameters: the first type was related to the commuter's socio-economic characteristics, whereas the second was related to transport facility characteristics.

Different socio-economic and transport-facility-related variables were considered while estimating the model, and based on their levels of significance some of them were incorporated into the final model. The levels of each transport facility attribute were entered into the model and were assumed to be provided by an AMTIS according to the SP design. This would enable the identification of two important aspects of the disseminated integrated traveller information: first, the usage of the provided information by the commuters and second, the significant attributes that are considered important by the commuters. The sign convention, estimated coefficient values and their corresponding significance levels are presented in Table 3 . All the included variables were significant at the $90 \%$ confidence level. The likelihood static ratio shows that the model was significantly different from the null or intercept-only (or know-nothing) model by the $\chi^{2}$ value ( 74.8 with 10 degrees of freedom). All the variables have coefficients significantly different from 0 , as judged by the size of $\beta$ relative to its estimated asymptotic standard error, and further indicated by the column labelled $P$, which gives the upper bound of the probability of making a type 1 error. The lower value of the log likelihood function and the estimated value of $\rho^{2}$ reflect the robustness of the estimated model (Cramer, 1999; Rana et al., 2010). These test statistics show that the model can describe the mode choice process well.
The utility functions for the private $\left(U_{\mathrm{PR}}\right)$ and public $\left(U_{\mathrm{PB}}\right)$ modes of transport are

$$
\begin{aligned}
U_{\mathrm{PR}}= & 5.731-0.665(\text { Travel time difference }) \\
& -0.330(\text { Travel cost difference })-1.970(\text { Gender }) \\
& +3.929(\text { Age })+1.137(\text { Education })+1.402(\text { Income })
\end{aligned}
$$

4.

$$
\begin{aligned}
U_{\mathrm{PB}}= & -2 \cdot 478(\text { Access mode })-1 \cdot 759 \text { (Access time }) \\
& -2 \cdot 514(\text { Waiting time })+3 \cdot 161 \text { (Seat availability })
\end{aligned}
$$

The estimated model consists of one alternative specific constant, four socio-economic variables and six transport facility attributes. The sign convention of each variable provides the information from which the commuters' mode-switching behaviour can be analysed. The positive value of the alternative specific constant shows that the commuters tended more towards the private mode of transport as compared to the public mode. The model results show that female commuters were more likely to continue using their usual modes of transport as compared to male commuters. Such behaviour can be interpreted as follows: with the provision of information, male commuters showed a higher tendency to switch from the private to the public mode of transport as compared to females. This may be attributable to a lower tolerance level of congestion among males. Commuters in a higher age group with a high level of education showed a greater tendency to use the private mode. This could be due to their cohort's value as discussed

\begin{tabular}{|c|c|c|c|c|}
\hline Socio-economic & $\boldsymbol{\beta}$ & t-Statistic & Standard error & $P$ \\
\hline Constant & $5 \cdot 731$ & $2 \cdot 253$ & $2 \cdot 544$ & 0.024 \\
\hline Gender (ref. = male) & -1.97 & $-1 \cdot 833$ & 1.075 & 0.067 \\
\hline Age (ref. = age group 18 to 35 years) & 1.929 & $3 \cdot 016$ & $1 \cdot 303$ & 0.003 \\
\hline Level of education (ref. = pre-university and below) & $1 \cdot 137$ & $2 \cdot 066$ & 0.55 & 0.039 \\
\hline Level of income (ref. $=$ income group less than $\$ \$ 1500$ ) & $1 \cdot 402$ & $2 \cdot 287$ & 0.613 & 0.022 \\
\hline Transport facility attributes & $\boldsymbol{\beta}$ & t-Statistic & Standard error & $P$ \\
\hline Access mode to MRT station (ref. = walk) & $2 \cdot 478$ & $2 \cdot 108$ & $1 \cdot 176$ & 0.035 \\
\hline Access time to MRT station & 1.759 & 1.65 & 1.087 & $0 \cdot 105$ \\
\hline Waiting time at MRT station & $2 \cdot 514$ & $2 \cdot 212$ & $1 \cdot 137$ & 0.027 \\
\hline Seat availability (ref. = seat is not available) & $-3 \cdot 161$ & $-2 \cdot 163$ & $1 \cdot 462$ & 0.031 \\
\hline Travel time difference: min & -0.656 & $-2 \cdot 172$ & $0 \cdot 302$ & 0.03 \\
\hline Travel cost difference: $\mathbf{S \$}$ & -0.33 & $-2 \cdot 585$ & $0 \cdot 128$ & 0.01 \\
\hline Summary statistics & & & & \\
\hline Number of observations & \multicolumn{4}{|c|}{400} \\
\hline Log likelihood function & \multicolumn{4}{|c|}{$-56 \cdot 343$} \\
\hline Restricted log likelihood & \multicolumn{4}{|c|}{$-225 \cdot 522$} \\
\hline Degrees of freedom & \multicolumn{4}{|c|}{390} \\
\hline$\chi^{2}$ & \multicolumn{4}{|c|}{$74 \cdot 808$} \\
\hline$\rho^{2}$ & \multicolumn{4}{|c|}{0.663} \\
\hline
\end{tabular}
by Sun et al. (2012), and/or the level of comfort and/or privacy that they may desire with respect to their socio-economic status. The commuters with lower income levels tended to

Table 3. Mode choice logit model estimating the commuter's mode choice behaviour, given integrated multimodal traveller information 
switch from private mode to public mode. This may be for reasons of cost saving, as the parking cost and ERP charges were increased in the scenario presented to respondents.

Among the transport facility attributes, commuters prefer to have MRT stations near to their residence, within walking distance, as walking is the preferred mode of access. This could be because travelling by bus to MRT stations increases the overall waiting time and the number of transfers. Lower access time is preferred, as it can save the effort used in travelling. Commuters naturally prefer low waiting times. Increased waiting time at MRT stations decreases the tendency to take the public mode of transport.

The negative signs of TTD and TCD, which refer to the travel time difference between private and public modes of transport and the travel cost difference between private and public modes of transport, show that commuters' likelihood of mode switching can be increased by increasing the absolute values of these variables. The TTD and TCD can be estimated as

\section{5a. $\quad \mathrm{TTD}=\mathrm{TT}_{\mathrm{PR}}-\mathrm{TT}_{\mathrm{PB}}$}

and

\section{5b. $\quad \mathrm{TCD}=\mathrm{TC}_{\mathrm{PR}}-\mathrm{TC}_{\mathrm{PB}}$}

where $\mathrm{TT}_{\mathrm{PR}}$ is the travel time by private mode of transport; $\mathrm{TT}_{\mathrm{PB}}$ is the travel time by public mode of transport; $\mathrm{TC}_{\mathrm{PR}}$ is the travel cost by private mode of transport; and $\mathrm{TC}_{\mathrm{PB}}$ is the travel cost by public mode of transport. Increasing the value of travel time on the private mode of transport as compared to the public mode of transport would increase the TTD, resulting in less likelihood of the private mode of transport being chosen. In other words, increasing the value of TTD would result in higher mode switching, as compared to a lower TTD value. Thus, by analysing the TTD and TCD, it can be inferred that increasing travel time or cost on any mode will decrease its utility. Furthermore, increase in travel time or cost of the private mode would enhance commuters' mode-switching propensity.

\subsection{Marginal effect of the estimated logit variables}

The exponential values of $\beta$ give the odds of having an event occurring as opposed to not occurring, per level change in the explanatory variables, other things being equal. The same interpretation applies to both the dummy and the continuous variables. From Table 3, it can be observed that the estimate for gender is -1.97 . The resulting exponential value of $P$, which is $\exp (1 \cdot 97)=7 \cdot 17$, indicates that the odds for males are $7 \cdot 17$ times as high as they are for females of switching their usual mode of travel. Hence, males have a higher probability of switching their modes of travel as compared to females.
The level of income has a negative impact on mode-switching propensity. Increasing the level of income decreases mode switching, and vice versa. The effect of each stage of income (i.e. 0, 1, 2, 3 and 4) on the odds of maintaining the usual mode of travel under the influence of integrated traveller information is 1.402 .

The transport facility characteristics - the travel time difference and travel cost difference - both significantly affected the automobile commuter's mode-switching propensity under the influence of integrated traveller information. It is estimated that each minute increase in travel time difference increases the mode-switching propensity by a factor of $\exp (0 \cdot 656)=1.927$. Similarly, each dollar increase in cost difference increases mode switching by a factor of $\exp (0 \cdot 33)=1 \cdot 392$.

\subsection{Predicted probabilities based on the explanatory variables}

The predicted probabilities based on the explanatory variables can provide estimates, upon which different policies can be designed and analysed. It should be noted that variables such as travel time and travel cost can be utilised to design policies which can cause a diversion effect in terms of mode shifting from a private to a public mode of transport. There are several measures to reduce travel time by public mode of transport, such as improvements in accessibility or service frequency and so on. Similarly, increasing parking cost and ERP charges can directly influence the decision to travel by the public mode of transport. To analyse the impact of such policy-sensitive variables, a pivot point modelling approach was adopted. The results are presented in Table 4.

The results in Table 4 reveal that every $10 \%$ increase in travel time in the private mode, on average, decreased the modal share of the private mode by $1 \cdot 22 \%$. Similarly, every $10 \%$ increase in travel cost of the private mode decreased its modal share by $0.56 \%$.

\subsection{Marginal effect on the probability of} commuter's mode-switching propensity

Instead of examining the marginal effect of an $x$ variable on the odds, it is possible to examine the marginal effect of the variable on the probability of the event. Such a marginal effect is given by the following equation

6. $\quad \frac{\partial \operatorname{Prob}(y=0)}{\partial x_{k}}=\frac{\mathrm{e}^{-\sum_{k=1}^{K} \beta_{k} x_{k}}}{\left(1+\mathrm{e}^{-\sum_{k=1}^{K} \beta_{k} x_{k}}\right)} \beta_{k}$

Table 5 presents the marginal effects of the variables on the probability of an automobile commuter's mode-switching propensity. Observing the marginal effect column, it can be seen that, among the socio-economic variables, the most significant 
Table 4. Impact on modal split by increasing travel time and travel cost of private mode of transport

\begin{tabular}{|c|c|c|c|c|c|c|}
\hline \multirow[b]{2}{*}{ Unit change: \% } & \multicolumn{3}{|c|}{ Travel time } & \multicolumn{3}{|c|}{ Travel cost } \\
\hline & Private mode: \% & Public mode: $\%$ & Diff.: \% & Private mode: \% & Public mode: \% & Diff.: \% \\
\hline 10 & $80 \cdot 01$ & 19.99 & 1.07 & $80 \cdot 52$ & $19 \cdot 48$ & 0.52 \\
\hline 20 & 78.94 & 21.06 & 1.07 & 80 & 20 & 0.52 \\
\hline 30 & $77 \cdot 82$ & $22 \cdot 18$ & $1 \cdot 11$ & $79 \cdot 46$ & $20 \cdot 54$ & 0.53 \\
\hline 40 & $76 \cdot 67$ & $23 \cdot 33$ & $1 \cdot 15$ & $78 \cdot 92$ & 21.08 & 0.54 \\
\hline 50 & $75 \cdot 48$ & $24 \cdot 52$ & $1 \cdot 19$ & $78 \cdot 36$ & $21 \cdot 64$ & 0.56 \\
\hline 60 & $74 \cdot 24$ & $25 \cdot 76$ & $1 \cdot 23$ & $77 \cdot 8$ & $22 \cdot 2$ & 0.57 \\
\hline 70 & 72.97 & 27.03 & 1.27 & $77 \cdot 22$ & $27 \cdot 78$ & 0.58 \\
\hline 80 & 71.66 & $28 \cdot 34$ & $1 \cdot 31$ & 76.64 & $23 \cdot 36$ & 0.59 \\
\hline 90 & $70 \cdot 31$ & $29 \cdot 69$ & 1.35 & 76.04 & 23.96 & 0.6 \\
\hline 100 & 68.92 & 31.08 & $1 \cdot 39$ & 75.43 & 24.57 & 0.61 \\
\hline Average & & & $1 \cdot 22$ & & & 0.56 \\
\hline
\end{tabular}

Table 5. Effects of the variables on the probability of commuters' mode-switching propensity

\begin{tabular}{|c|c|c|c|}
\hline Variable & Coefficient, $\beta$ & Mean & Marginal effect \\
\hline \multicolumn{4}{|l|}{ Socio-economic } \\
\hline Gender & 1.970 & 0.543 & 0.725 \\
\hline Age: years & -1.930 & $1 \cdot 491$ & -0.710 \\
\hline Level of education & $-1 \cdot 137$ & 1.750 & $-0 \cdot 418$ \\
\hline Level of income: $\mathbf{S \$}$ & $-1 \cdot 402$ & $2 \cdot 241$ & -0.516 \\
\hline \multicolumn{4}{|l|}{ Transport facility } \\
\hline Access mode to MRT station & $-2 \cdot 479$ & 0.578 & -0.912 \\
\hline Access time to MRT station & $-1 \cdot 760$ & 0.750 & -0.647 \\
\hline Waiting time at MRT station & $-2 \cdot 514$ & 0.664 & -0.925 \\
\hline Seat availability & $3 \cdot 162$ & 0.690 & $1 \cdot 163$ \\
\hline Travel time difference: $\min$ & 0.656 & $2 \cdot 414$ & $0 \cdot 241$ \\
\hline Travel cost difference: $S \$$ & 0.330 & $2 \cdot 202$ & $0 \cdot 122$ \\
\hline
\end{tabular}

effects are gender and age, followed by income and education, in that order.

Looking at the transport facility variables, the sensitive variable is the waiting time for transit service. Each single minute increase in travel time reduces the mode-switching propensity by a factor of 0.925 . This analysis can also be viewed from another perspective, which is that any improvement in the waiting time reduction can cause a significant impact on mode choice, such that a 1 min reduction in waiting time will increase the mode-switching propensity by a factor of 0.925 . A similar kind of effect can be observed for the access time variable. The time difference and cost difference, which in this case represent the time savings and cost savings on a public mode of transport, respectively, also show a positive effect on the automobile commuter's mode-switching propensity.

It can be concluded from this analysis that automobile commuters show a certain level of mode-switching propensity under the influence of integrated traveller information. Younger male automobile commuters with a lower level of income are more willing to switch their usual mode of transport, as compared to richer and better-educated automobile commuters. The cost factor also influences the mode choice, such that if the automobile commuter belongs to a lower-level income group he/she may show higher mode-switching propensity. Richer automobile commuters with a higher level of education are less willing to switch. Time and cost savings are appreciated by all automobile commuters. In the context of time, automobile commuters are more sensitive to waiting time than travelling time. They choose modes with overall shorter journey times. Cost savings enhance the attraction of the public mode of transport, which the automobile commuters compare with the higher cost of the private mode. Thus, the provision of integrated information regarding the transport facility variables can enhance the mode-switching propensity in automobile commuters.

\section{Conclusions}

The main objective of the travel behaviour survey was to determine the factors that influence a commuter's mode choice decision. It is clear from the estimated travel behaviour models (two SP scenarios) that the socio-economic characteristics that significantly influence the mode choice decision are gender, age, level of education and level of income. The attributes related to multimodal traveller information that significantly influence the mode choice decision in a congested road environment are the access mode to the MRT station, the access time to the MRT station and transit seat availability. Estimated time saving, estimated cost saving and waiting time at the MRT station also have a certain influence on the travel 
mode choice decision. Information regarding a delayed travel time generated the desire in commuters to access multimodal traveller information, and information on estimated time saving allowed the commuters to analyse different modes of travel. Information about transit facility also significantly influenced the mode choice decision, such that an improved level of service related to the transit can increase the number of transit passengers. The knowledge gathered from this travel behaviour survey provides valuable expertise to select variables that significantly influence the mode choice decision.

However, the model still has several limitations. There are also cases where the proposed model could not properly describe the traveller behaviour under different situations. For instance, different cities may have different influencing factors; a certain policy may strengthen or eliminate the effect from certain influencing factors. A model cannot be perfect or provide the best fit for all possible cases. Future studies will contribute to better understanding of traveller behaviour in more case scenarios.

\section{Acknowledgements}

This work was conducted under the $\mathrm{PhD}$ research programme of the second author (Dr Abdul Ahad Memon) at the Nanyang Technological University. The first author was financially supported by the Singapore National Research Foundation under its Campus for Research Excellence and Technological Enterprise (CREATE) programme.

\section{REFERENCES}

Adler JL (2001) Investigating the learning effects of route guidance and traffic advisories on route choice behaviour. Transportation Research C 9(1): 1-14.

Balakrishna R, Ben-Akiva M, Bottom J and Gao S (2013) Information impacts on traveler behavior and network performance: state of knowledge and future directions. In Advances in Dynamic Network Modeling in Complex Transportation Systems (Ukkusuri SV and Özbay KMA (eds)). Springer, New York, NY, USA, pp. 193-224.

Beirão G and Cabral JAS (2007) Understanding attitudes towards public transport and private car: A qualitative study. Transport Policy 14(6): 478-489

Bifulco GN, Cantarella GE, de Luca S and Di Pace R (2011) Analysis and modelling the effects of information accuracy on travellers' behaviour. In Proceedings of Intelligent Transportation Systems (ITSC), 14th International IEEE Conference. Institute of Electrical and Electronics Engineers (IEEE), New York, NY, USA, pp. 2098-2105.

Bradley M (2006) Process data for understanding and modelling travel behaviour. In Travel Survey Methods - Quality and Future Directions (Stopher P and Stecher C (eds)). Emerald Group Ltd, Bingley, UK, chapter 2, pp. 491-511.

Buliung RN and Kanaroglou PS (2007) Activity-travel behaviour research: conceptual issues, state of the art, and emerging perspectives on behavioural analysis and simulation modelling. Transport Reviews 27(2): 151-187.

Chorus CG, Arentze TA, Molin EJ, Timmermans HJP and van Wee B (2006) The value of travel information: decision strategy-specific conceptualizations and numerical examples. Transportation Research B 40(6): 504-519.

Chorus CG, Walker JL and Ben-Akiva M (2013) A joint model of travel information acquisition and response to received messages. Transportation Research C 26: 61-77.
Cramer JS (1999) Predictive performance of the binary logit model in unbalanced samples. Journal of the Royal Statistical Society: Series D (The Statistician) 48(1): 85-94.

De Witte A, Hollevoet J, Dobruszkes F, Hubert M and Macharis C (2013) Linking modal choice to motility: a comprehensive review. Transportation Research A: Policy and Practice 49: 329-341.

Farag S and Lyons G (2008) Explaining public transport information use when a car is available: attitude theory empirically investigated. Transportation Research Record 2069: 85-92.

Farag S and Lyons G (2012) To use or not to use? An empirical study of pre-trip public transport information for business and leisure trips and comparison with car travel. Transport Policy 20: 82-92.

Golob TF (2003) Structural equation modeling for travel behavior research. Transportation Research B 37(1): 1-25.

Guo Z (2011) Mind the map! The impact of transit maps on path choice in public transit. Transportation Research A 45(7): 625-639.

Jou RC, Lam SH, Liu YH and Chen KH (2005) Route switching behaviour on freeways with the provision of different types of real-time traffic information. Transportation Research A 39(5): 445-446.

Kenyon S and Lyons G (2003) The value of integrated multimodal traveller information and its potential contribution to modal change. Transportation Research F 6(1): 1-21.

Lam SH and Memon AA (2003) Development of an Intelligent Traffic Simulation Model (InSim) for Evaluating the Effects of Multimodal Traveller Information. Australian Road Research Board (ARRB) Transport Research Limited, Cairns, Australia.

Luk J and Yang C (2003) Comparing driver information systems in a dynamic modelling framework. Journal of Transportation Engineering 129(1): 42-50.

Parvaneh Z, Arentze T and Timmermans H (2012) Understanding travelers' behavior in provision of travel information: a Bayesian belief approach. Procedia - Social and Behavioral Sciences 54: 251-260.

Qin HM, Guan HZ and Wu YJ (2013) Analysis of park-and-ride decision behavior based on decision field theory. Transportation Research F 18: 199-212.

Rana S, Midi H and Sarkar SK (2010) Validation and performance analysis of binary logistic regression model. Proceedings of the WSEAS International Conference on Environmental, Medicine and Health Sciences, Penang, Malaysia, pp. 23-25.

Sun YL, Waygood EOD and Huang Z (2012) Do automobility cohorts exist in urban travel? Case study of Osaka metropolitan area, Japan. Transportation Research Record 2323: 18-24.

Zito P, Amato G, Amoroso S and Berrittella M (2011) The effect of advanced traveller information systems on public transport demand and its uncertainty. Transportmetrica 7(1): 31-43.

\section{How can you contribute?}

To discuss this paper, please email up to 500 words to the editor at journals@ice.org.uk. Your contribution will be forwarded to the author(s) for a reply and, if considered appropriate by the editorial board, it will be published as discussion in a future issue of the journal.

Proceedings journals rely entirely on contributions from the civil engineering profession (and allied disciplines). Information about how to submit your paper online is available at www.icevirtuallibrary.com/page/authors, where you will also find detailed author guidelines. 